\title{
GCU
}

Glasgow Caledonian

University

University for the Common Good

\section{A non-invasive preferential root distribution analysis methodology from a slope stability approach}

Tardio, Guillermo; Gonzalez-Ollauri, Alejandro; Mickovski, Slobodan B.

Published in:

Ecological Engineering

DOI:

10.1016/j.ecoleng.2016.08.005

Publication date:

2016

Document Version

Author accepted manuscript

Link to publication in ResearchOnline

Citation for published version (Harvard):

Tardio, G, Gonzalez-Ollauri, A \& Mickovski, SB 2016, 'A non-invasive preferential root distribution analysis methodology from a slope stability approach', Ecological Engineering, vol. 97, pp. 46-57.

https://doi.org/10.1016/j.ecoleng.2016.08.005

\section{General rights}

Copyright and moral rights for the publications made accessible in the public portal are retained by the authors and/or other copyright owners and it is a condition of accessing publications that users recognise and abide by the legal requirements associated with these rights.

Take down policy

If you believe that this document breaches copyright please view our takedown policy at https://edshare.gcu.ac.uk/id/eprint/5179 for details of how to contact us. 


\title{
A non-invasive preferential root distribution analysis methodology from a slope stability approach
}

Guillermo Tardío ${ }^{1}$, Alejandro González-Ollauri², Slobodan B. Mickovski ${ }^{2}$

\author{
${ }^{1}$ Technical University of Madrid. Avenida Niceto Alcalá Zamora, 6, 4D. 28905 Getafe \\ (Madrid). Spain. Tel: ++34 9117283 60, e-mail: gtarcer@gmail.com \\ ${ }^{2}$ School of Engineering and Built Environment, Glasgow Caledonian University, 70 \\ Cowcaddens Rd, G4 OBA, Glasgow, Scotland, UK
}

\begin{abstract}
Asymmetric root distribution pattern on steep terrain is analysed by combining GPR (Ground Penetrating Radar) image analysis with a theoretical root distribution model and is verified with field investigation data. Root distribution and morphology of a mature deciduous tree were analysed in terms of the plant's anchorage needs in an asymmetric loading condition scenario. The GPR method was combined with trench profile and root excavation techniques for both the structural and non-structural root data collection.

Good correlations between the field analysis, the theoretical model outcome and the GPR output imagery were found. GPR was proven to be an efficient tool for both root lateral distribution characterisation and vertical root cluster distribution. The combination of the GPR output with a theoretical root distribution model seemed to be a viable non-invasive methodology for assessing root system vertical and horizontal distribution.
\end{abstract}

Keywords: GPR, root distribution, slope conditions, root mechanics, hydromorphy, root asymmetry, tree stability, root anchorage. 


\section{Introduction}

The importance of root system architecture for the stability of trees has received considerable attention in the past 30 years (Coutts, 1983; Crook and Ennos, 1996; Nicoll and Ray, 1996; Stokes et al., 1996; Stokes et al., 1997; Mickovski and Ennos, 2001; Chiatante et al., 2003). A number of studies (Mattheck et al., 1995; Chiatante et al., 2003; Coder, 2010; Mattheck, 2011) concluded that sloping terrain remarkably affects the tree root distribution in the soil. In flat areas, roots systems are usually symmetrical, following a so called "symmetrical bell-shape" pattern (Chiatante et al., 2003). In sloped areas, root distribution is no longer symmetrical and follows a so-called "bilateral fan-shape" pattern (Chiatante et al., 2003) as a morphological adaptation of the plant to inclined topographies.

To efficiently anchor themselves and prevent overturning or uprooting, the trees must transfer the loading forces into the ground via the roots (Stokes and Guitard, 1997). Specific anchorage patterns with respect to the slope plane may develop in plants growing on slopes in order to prevent overturning in a downslope direction (Mattheck et al., 1995; Chiatante et al., 2001). Different studies suggested that both large root surface area and asymmetric root architecture laterally around the trunk improve tree anchorage on a slope by increasing the resistance to overturning forces (Chiatante et al., 2001; Chiatante et al., 2003). These results connect with the idea that a bigger interbonding surface between roots and the surrounding soil is needed in the upslope area in order to mobilise friction between root and soil to counterbalance the tensile stresses generated due to the overturning driving forces the tree roots are subjected to when growing on slopes (Mattheck et al., 1995; Mattheck, 2011; Stokes and Guitard, 1997). This adaptation arrangement has been observed for a number of woody species (Chiatante et al., 2003), and similar traits have been observed in various plants subject to different, usually lateral, disturbing forces (e.g. wind; Mattheck, 2011).

The hydromechanical effects of trees on slope stability have been thoroughly studied during the past decade (Pollen and Simon, 2005; Norris et al., 2008; Stokes et al., 2009; Preti and Giadrossich, 2009; Schwarz and Lehman, 2010; Fan, 2012; Bourrier et al., 2013), 
leading to a number of models that include both the beneficial and unfavourable effects. Because of the variety and extent of these effects, all of the existing models to estimate the root contribution to slope stability need relatively detailed root morphology information. Direct methods (Böhm, 1979; Van Noordwijk et al., 2000) to obtain root spread information are both labour-intensive and destructive. Therefore, there is a need for cost-effective non-invasive methodologies for root system morphology investigation.

The most recent theoretical root distribution models are based on long term water mass balance in the soil (e.g. Laio et al., 2006) and developed for flat terrain. Additionally, these models do not consider mechanical variables that take into account root anchorage functions. Therefore, a complementary source of information may enhance the description of the root system spread for sloped topographies and lead to development of better hydrological-mechanical models of tree behaviour on slopes. To the authors' knowledge, an approach that portrays the widely-observed root spread and its application to stability analysis on sloped terrain has not been proposed yet. Methodologies improving the description and modelling of root distribution laterally from the tree trunk are needed because of their direct impact in defining and estimating the distribution of lateral root reinforcement (Schwarz and Lehman, 2010). In the presence of significant lateral root reinforcement, the area that must be destabilized in order to trigger a landslide will increase (Reneau and Dietrich, 1987). This is particularly relevant in shallow failure prone slopes where the roots are most likely to have a major effect on the stability of the soil mass either by anchoring it (structural roots; Mickovski and Ennos, 2003) or binding the soil together and protecting it from erosion (non-structural and fibrous roots; Mickovski et al., 2005).

The use of non-invasive sub-surface ground analysis, along with the theoretical root distribution models, could provide valuable information about tree root system morphology. In this sense, Ground-penetrating radar (GPR) is a potentially suitable technology for detecting subsurface structural roots and creating root distribution maps. GPR is able to detect either large roots (diameter bigger than 10 mm; Stokes et al., 2002; Guo et al., 2013; Raz-Yaseef et al., 2013; Tanikawa and Ikeno, 2016) or fine root clusters (Bassuk et al., 
2011). Root system bulk properties, such as root density comparisons, could be performed with this technique as well (Butnor et al., 2003). GPR has been shown to successfully locate tree roots non-invasively and in three dimensions in forest soils (Hruska et al., 1997; Butnor et al., 2001; Stokes et al., 2002; Butnor et. al., 2003; Zenone et al., 2008). Despite the above lines of investigation, no applications of GPR investigations have been carried out with respect to slope stability analysis and root reinforcement models.

In this paper the existing theoretical models are used in combination with a noninvasive technology (GPR) in order to derive a more realistic root system morphological description for sloped conditions, without intention of generating a combined hydrologicalmechanical simulation model for root system architecture predictions. To achieve this aim, a field investigation campaign was carried out on a landslide-prone slope in northeast Scotland (UK). A GPR investigation of the root spread of a mature maple tree (Acer pseudoplatanus L.) growing on inclined terrain was carried out, before exposing relevant parts of the root system and recording the necessary tree metrics. The information obtained was used to validate the combined (GPR and theoretical root distribution model) methodology and to analyse the root system asymmetric shape from a mechanical point of view.

\section{Materials and methods}

\subsection{Background}

On an inclined plane, woody plant root systems usually develop a gravitropic taproot with a larger number of lateral roots growing preferentially upslope (Shrestha et al., 2000). The number of laterals growing upslope seems to increase with the slope angle, and the angle between the lateral roots growing downslope and the taproot is smaller than the angle between uphill lateral roots and the tap-root (Shrestha et al., 2000). The centre of gravity of the lateral roots biomass is located upslope with respect to the trunk (Mattheck, 2011). The asymmetry in these "bilateral-fan shape" (Chiatante et al., 2003) systems observed in many tree species is a response to the different functions of the upslope/downslope portion of the 
root system. The functions governing the root development on the slope would include the tree stability (mechanical) and availability of water/nutrients (hydrological).

Theoretical root distribution models (Laio et al., 2006; Preti et al., 2010) assume symmetrical root systems. Although some attempts have been made to incorporate the slope influence on the root spread (Tron et al., 2014), these attempts have been set in hydrologic and pedoclimatic terms, not taking into account anchorage function and mechanics. Other authors (e.g. Tsutsumi et al., 2003; Tsutsumi et al., 2004) have incorporated the slope influence by means of hydrotropism (root elongation towards water), resulting in a clear asymmetric pattern. However, these models do not explain the occurrence of lateral roots with larger diameters in the upslope direction (Chiatante et al., 2003).

The optimisation of the root system development under different loading conditions has been investigated from a mechanistic aspect (e.g. Mattheck, 2011; Mattheck and Bethge, 2011) and can be visualised using a finite element method code (e.g. SKO-Soft Kill Option) (Baumgartner et al., 1992). The asymmetry in the root systems growing on slopes (more and bigger lateral roots growing upslope in comparison to the downslope direction; Fig. 1) is driven by the asymmetric loading; (Mattheck, 2001).

A)

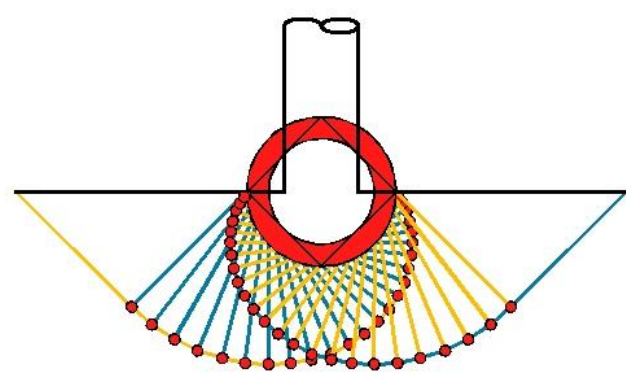

B)

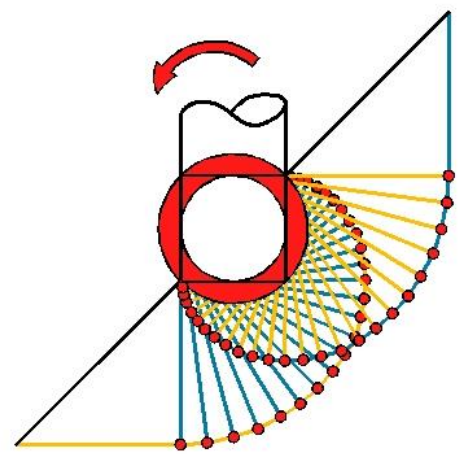

Figure 1 Compression (in blue) and tension (in yellow) force distributions in a safe root anchorage A) flat, B) sloped terrain conditions, the latter giving place to an asymmetric loading scenario (red arrow). Adapted from Mattheck and Bethge (2011).

The distribution of roots decreases with depth under the soil surface. This distribution, expressed as Root Area Ratio (RAR; ratio of cross section of roots and the soil cross section at depth $z$ below ground) can be modelled using existing methods (e.g. Laio et 
al., 2006; Preti et al., 2010) as an exponentially decreasing function of soil depth and the average rooting depth (Preti et al., 2010; Eq. 2, Table 1) requiring readily available long-term climatic and pedological parameters and a species-specific scaling factor. In these models, the average rooting depth estimation is problematic for humid climate cases since, when using Laio et al (2006) model, the $b_{m}$ value can become negative (Tron et al., 2014).

Table 1 Equations and parameters for the root reinforcement calculation (Laio et al., 2006; Preti et al., 2010)

\begin{tabular}{|l|l|}
\hline$R A R(z)=\frac{A r(z)}{A r s} \quad$ Eq. 1 & $\begin{array}{l}\operatorname{RAR}(\mathrm{z})=\text { root area ratio at the depth } \mathrm{z} \\
\operatorname{Ar}(\mathrm{z})=\text { roots cross sectional area with depth } \\
\left(\mathrm{m}^{2}\right) \\
\operatorname{Ar}(z)=A r_{0} e^{\frac{-z}{b_{m}}} \quad \text { Eq. 2 }\end{array}$ \\
& $\begin{array}{l}\mathrm{z}=\text { soil depth }(\mathrm{m}) \\
\operatorname{Ars}=\text { rooted soil area }\left(\mathrm{m}^{2}\right) \\
\operatorname{Ar}_{0}=\text { roots cross sectional area at } \mathrm{z}=0\left(\mathrm{~m}^{2}\right) \\
\mathrm{b}_{\mathrm{m}}=\text { mean rooting depth }(\mathrm{m})\end{array}$ \\
\hline
\end{tabular}

Since the Laio et al (2006) model was developed from a hydrological point of view, it limits the possibilities to incorporate mechanical variables. Hence, if the model output is to be used and combined with other features (e.g. the slope condition, different loading scenarios, etc.), the model outputs need to be modified instead of attempting to include a set of virtual factors within the model in order to simulate the mechanical effects such as the slope of the terrain. The mechanical effects and the corresponding asymmetric root distribution pattern could be incorporated by both a root volume transformation coefficients obtained from in situ investigations. With this, the assumption of a conical shape of the root volume (Preti et al., 2010; Gonzalez-Ollauri and Mickovski, 2016), will be replaced with a realistic root distribution and the humid climate condition limitation (Laio et al., 2006; Preti et al., 2010; Tron et al., 2014) will be overcome.

Ground Penetrating Radar (GPR) is a pulsed electromagnetic technique that generates a two-dimensional section of the subsurface in a manner very similar to reflection seismics, 
originally developed as a tool for investigating geological structures (Annan and Davis, 1976; Olhoeft, 1984; Davis and Annan, 1989). As in geotechnical sub-surface surveys, the combination of GPR and intrusive investigation is a common strategy for the verification and confirmation of the obtained results (e.g. GPR and borehole campaign; Singh, 2006) and, we have used this approach in our study to analyse the preferential root distribution/growth on sloping ground which is one of the novel aspects of our investigation.

\subsection{Approach/methodology}

The mean rooting depth value $\left(b_{m}\right)$ predicted by the existing models (e.g. Laio et al., 2006; Preti et al., 2010), which is a third of the total depth value (Laio et al., 2006; GonzalezOllauri and Mickovski, 2016), is valid both at plant community level and for water controlled ecosystems and flat areas. When analysing a root system at an individual tree level and in sloping conditions, the value of $b_{m}$ must be adjusted to account for the asymmetry in the root horizontal/vertical distribution. This new value of $b_{m}$ which is site- specific, could be directly obtained by the use of the GPR readings regarding the detected root vertical and lateral distribution pattern (Butnor et al., 2003; Butnor et al., 2011; Bassuk et al., 2011). By analysing the detected vertical and lateral root distribution pattern around the tree trunk, a mean rooting depth value can be obtained at various distances from the tree trunk. In the case of taproot systems, as the GPR readings are taken at a certain distance from the tree trunk, measurements right below the tree stem will not be possible for trees growing on a flat terrain while, on inclined planes, the detection of the tap root depth will be more feasible (Figure 2). In the case of tap root detection, the depth readings away from the tree stem will be shallower than those of the actual tap root tip depth and, hence, erring on the side of safety. With the preceding methodology it will be ensured that all information related to specific slope conditions is implicitly taken into account in the root depth estimation both in a non-invasive and in a conservative manner.

The variation of root distribution with depth $(\operatorname{Ar}(z)$, Preti et al., 2010; Eq 2) is related to a depth both parallel to the ground surface and perpendicular to the cone height. For 
maintaining the conic shape of the root volumetric distribution (Preti et al., 2010; GonzalezOllauri and Mickovski, 2016), on sloped terrain, the volume occupied by the roots is assumed to follow an asymmetric elliptic cone distribution. The height of this volume is related to the average rooting depth in the vertical direction (Fig. 2) according to Eq. 3.

$$
h^{\prime}=3 \cdot b_{m}^{\prime}=3 \cdot b_{m} \cdot \cos (\beta)=h \cdot \cos (\beta) \quad \text { Eq. } 3
$$

Where:

$\mathrm{h}=$ root system depth in the vertical direction $(\mathrm{m})$

$h^{\prime}=$ height of the asymmetric elliptic cone (perpendicular to the ground surface) $(m)$

$\beta=$ slope angle $(\stackrel{\circ}{)}$

$\mathrm{b}_{\mathrm{m}}=$ average rooting depth in the vertical direction $(\mathrm{m})$.

$b_{m}^{\prime}=$ average rooting depth in sloping conditions (Fig. 2) directly assessed by analysing GPR output images (m).

Hence, the rooted soil area can then be calculated with reference to an axis perpendicular to the ground surface ( $\mathbf{z}^{\prime}$; Figure 2) by using the same GPR readings. With this, the root distribution will be described according to planes parallel and perpendicular to the ground surface.

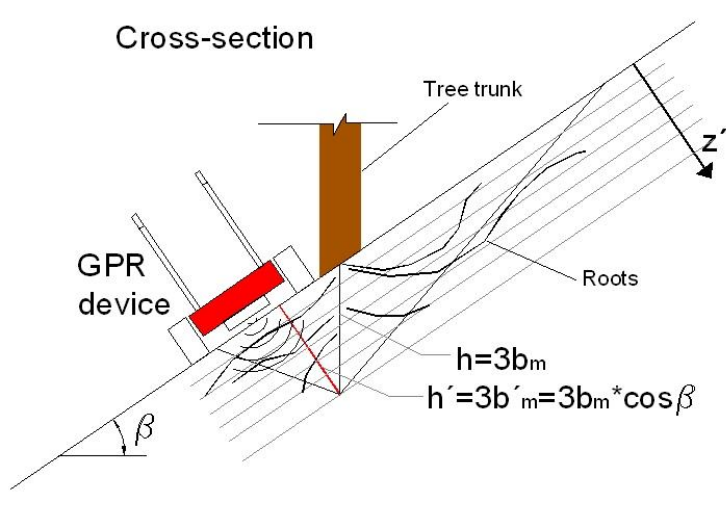

Figure 2 Root distribution laterally and in depth from the tree trunk shown in cross-section of a slope as investigated using a GPR device. $\mathbf{b}_{\mathbf{m}}{ }_{\mathrm{m}}$ is the average rooting depth in sloping conditions used in the exponential root distribution model.

To illustrate this approach, we identified a suitable site (see site general description section) and carried out the following steps: 
1. $\mathrm{Ar}_{0}$ was obtained by measuring the root collar area (Preti et al., 2010).

2. $b_{m}^{\prime}$ was obtained by analysing, from the GPR image processing (see GPR image processing section), the vertical root distribution information. By using $b_{m}^{\prime}$ and the $\mathbf{z}^{\prime}$ axis, Eq. 2 can be rewritten (Equation 4) where root area distribution according to planes parallel to the ground (Figure 2) can be calculated.

$$
\operatorname{Ar}\left(z^{\prime}\right)=A r_{0} e^{\frac{-z^{\prime}}{b_{m}^{\prime}}}
$$

Eq. 4

3. The model was compared and validated against the field data.

\subsection{Case study and model validation}

\subsubsection{General site description}

The study site lies in Catterline Bay, northeastern Scotland, UK (UTM 30V x: 547641 $y: 6305896)$ (Figure 3). The site is within the maritime climate zone with warm summers and cool winters. The precipitation is relatively evenly dispersed throughout the year (McKnight \& Hess, 2000).

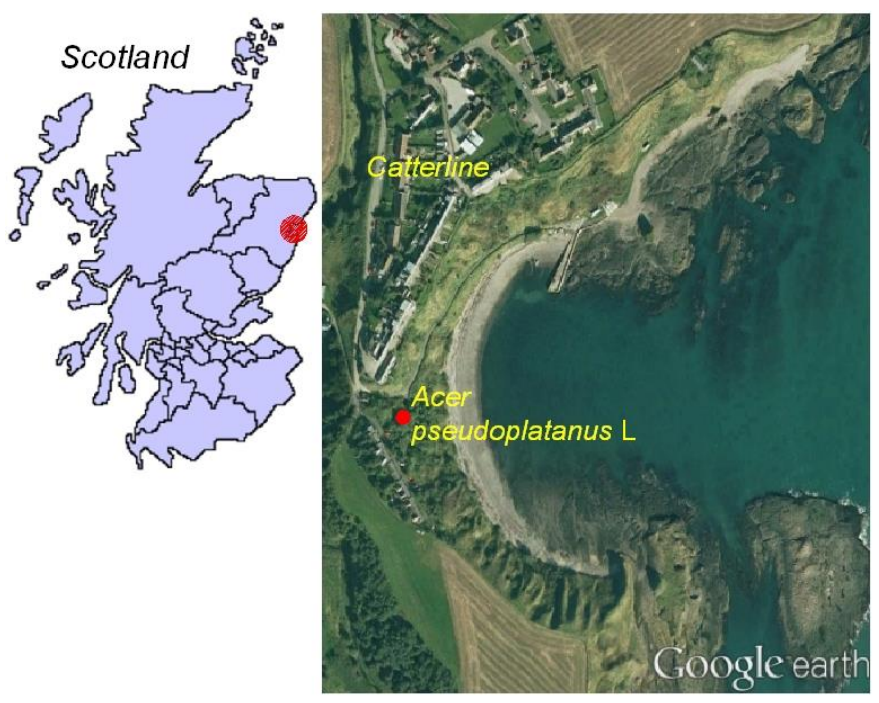

Figure 3 Analysed Acer pseudoplatanus L. location (Google Earth image @ 2016 Getmapping plc)

From a geomorphologic point of view, the study area is dominated by sloped terrain (slope gradient $=25^{\circ}-50^{\circ}$ ) including near-vertical sea cliffs. Shallow and well drained soils, 
predominantly silty sands, can be found within the study area resting on top of sedimentary bedrock (Catterline Conglomerate Formation; BGS, 2013).

\subsubsection{Non-intrusive field investigation of root distribution using GPR}

The GPR system consisted of a RD1000 ${ }^{\mathrm{TM}}$ model (SPX Corporation) with a 125-375 $\mathrm{MHz}$ radar bandwidth and a scanning screen (Figure 4B). Despite the limitedbandwidth of the GPR device and the antenna, the central frequency of $250 \mathrm{MHz}$ employed in this investigation was considered adequate for the detection of coarse elements such as structural roots and root clusters given both the sandy nature of the study area soil and its high water saturation level (device resolution lower than $0.075 \mathrm{~m}$; Robinson et al., 2013). Calibration of the GPR system was accomplished, in accordance with the manufacturer's specifications, by scanning a known object (cylindrical steel rod of diameter close to root diameters) buried at a known depth ( $0.24 \mathrm{~m}$; mimicking expected root depth) into the soil on site. The soil was sampled after calibration and the volumetric moisture content was measured using standard laboratory procedure (42.4\%; BS1377) in order to calibrate the readings and achieve better accuracy in GPR measurements.

Circular paths around a maple tree (Acer pseudoplatanus L.; Butnor et al., 2011) were followed to characterise tree root morphology and depth (Figure 4A). The circular path radii were limited by the presence of other trees around the selected maple but stretched as far as $2.5 \mathrm{~m}$ from the centre of the tree stem.

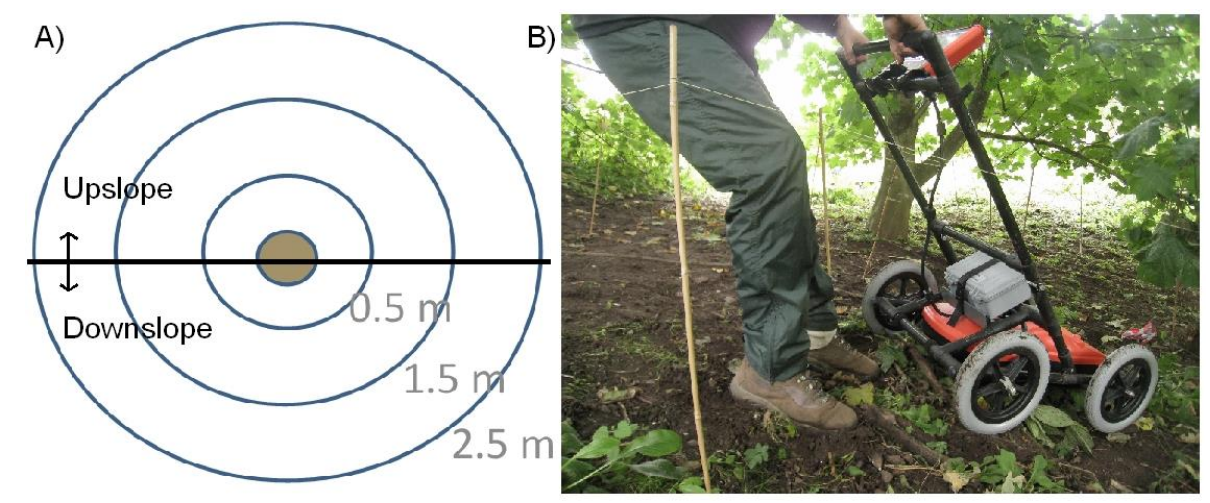

Figure 4 A) Circular paths around the maple stem, B) GPR set up marked on site with bamboo stakes. 
GPR readings from the concentric paths were taken and the root distribution around the stem and at different depths below ground was determined by recording the images of each scanned path. These images were processed and analysed in order to detect horizontal and vertical distribution patterns and tree roots superficial distribution (see Results section). Each circumference was divided in two halves, an upslope half-path and a downslope half-path, respectively (Figure 4A). By means of this framework it was possible to differentiate where the roots were more abundant and to determine and compare the root depths in both halves (upslope/downslope) of the path.

\subsubsection{Intrusive field investigation of root distribution}

After completing the non-intrusive investigation, the soil around the roots maple tree was removed within the topmost 200-300 mm (Böhm, 1979) (Figure 5B) depth and $2.5 \mathrm{~m}$ radius from the centre of the tree stem. Root length and root diameter measurements along the length of each root were taken with digital callipers and, for data point localization, angular sectors around the tree were defined (Figure 5A). The root distribution around the stem and below ground was mapped and comparisons with GPR root detection were made.
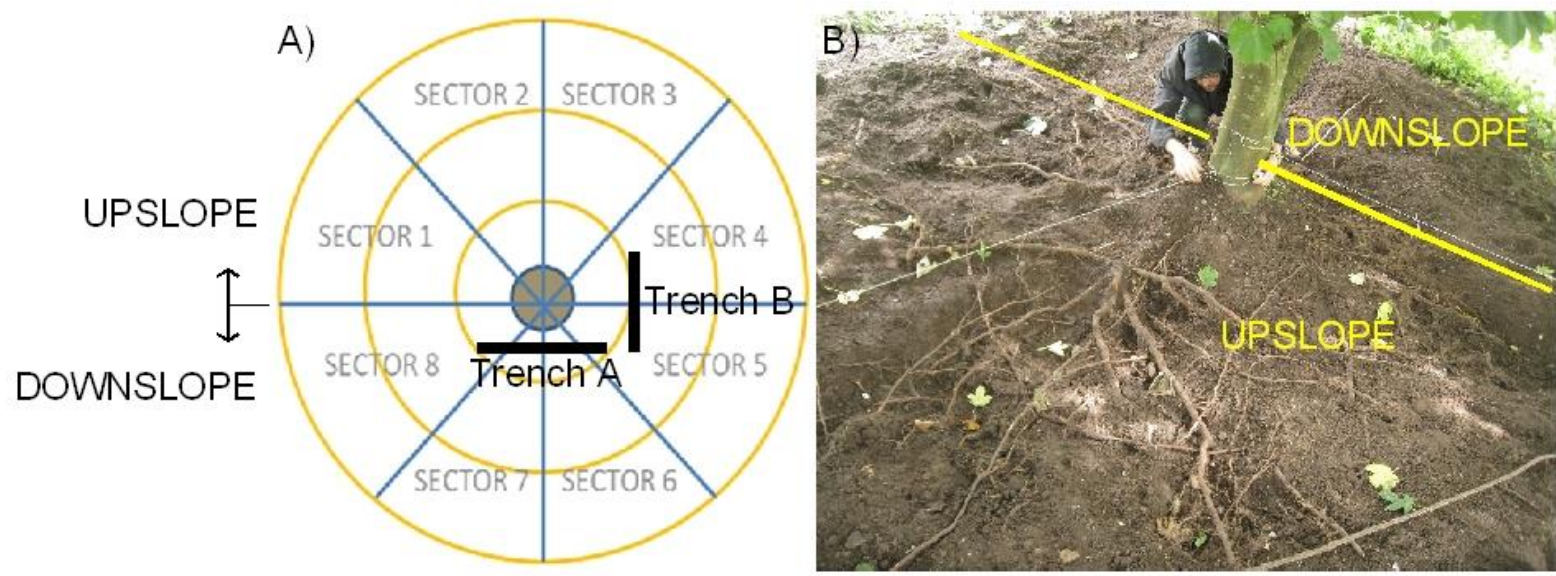

Figure 5 A) Sectors defined for root analysis, B) defining the sectors set up on site by means of ropes after root excavation works

To calibrate the root vertical distribution model output, the profile wall technique (Böhm, 1979) was used (Figure 6). Two trenches were excavated, one perpendicular to the slope (trench $\mathrm{A}=$ downslope trench) and another along the slope (trench $\mathrm{B}=$ lateral trench) (Figures 5A and 6). 


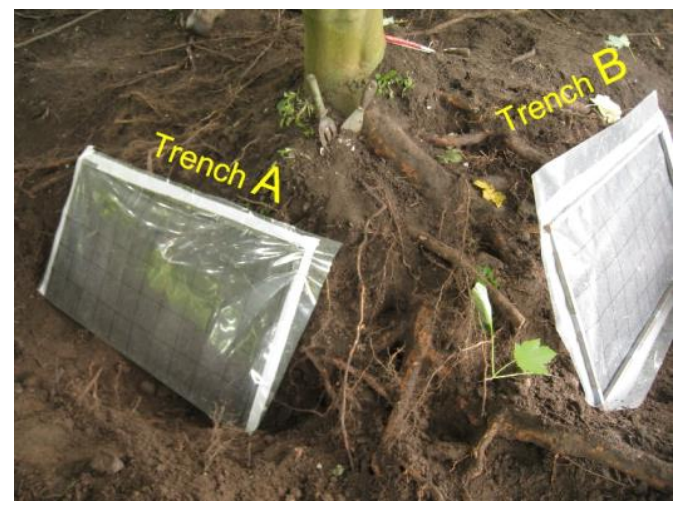

Figure 6 Profile trenches excavated during the field work campaign: downslope trench (trench A) and lateral trench (trench B)

\subsubsection{GPR image processing}

The series of radargrams retrieved from the GPR system were imported into the statistical freeware R 3.2.1 (R Core Team, 2014) and converted to .clmg format using the R package 'imager' (Barthelme, 2015). Each radargram was standardised (e.g. Guo et al., 2013) according to the distance covered by each GPR pass with respect to the captured depth (i.e. $1.15 \mathrm{~m}$ ) and the number of pixels contained in the original image (i.e. vertical = 459 pixels; horizontal $=640$ pixels $)$ by the application of a rule of three; ensuring that the spatial scale in the $X$ and $Y$ directions was the same at the end of the standardisation process, and so the area of soil covered by a pixel known in order to appraise the root area from the images. As result of the standardisation process, the number of pixels in the $X$ direction was extended. To extend the radargram, a nearest-neighbour interpolation was implemented. Once standardised, the radargrams were de-noised by blurring the images anisotropically (e.g. Barthelme, 2015). Then, each standardised and de-noised radargram was split into its colour bands (i.e. red, green and blue) and converted into a raster format with the R package 'raster' (Hijmans, 2014). The three raster bands were combined to generate a false colour raster using a RGB algorithm (Heckbert, 1982) in order to identify zones likely to present a root by the pixel colour (Figure 8). Then, the number of pixels was counted by establishing different pixel value thresholds. Eventually, the potential root area was estimated by multiplying the number of pixels by their resolution at four different depth 
intervals (i.e. $0-100 ; 200-300 ; 400-500 ; 500-600 \mathrm{~mm}$ ) and an exponential model was fitted between the calculated root area and the soil depth (Preti et al., 2010).

\section{Results}

\subsection{Site and vegetation characteristics}

The slope of the terrain was measured with a clinometer and showed a value of 22.5․ The above-ground tree biometrics recorded with a clinometer and measuring tape are shown in Table 2.

Table 2 Biometrics of the analysed individual of Acer pseudoplatanus $\mathrm{L}$.

\begin{tabular}{|l|c|}
\hline \multicolumn{1}{|c|}{ Variable } & Value \\
\hline Tree age (years) & 17 \\
\hline Tree height (m) & 7.17 \\
\hline Tree breast diameters (m) & $0.14 / 0.21$ \\
\hline Tree basal diameter (m) & 0.23 \\
\hline Root collar cross sectional area $\mathrm{Ar}_{0}(\mathrm{~m} 2)$ & 0.04 \\
\hline
\end{tabular}

Because of the competition from the surrounding trees, the tree crown was very asymmetric (Figure 7) and this situation, along with the slope condition, generated an asymmetric loading scenario, similar to the one shown in Figure $1 \mathrm{~b}$, that will be analysed later in this paper.

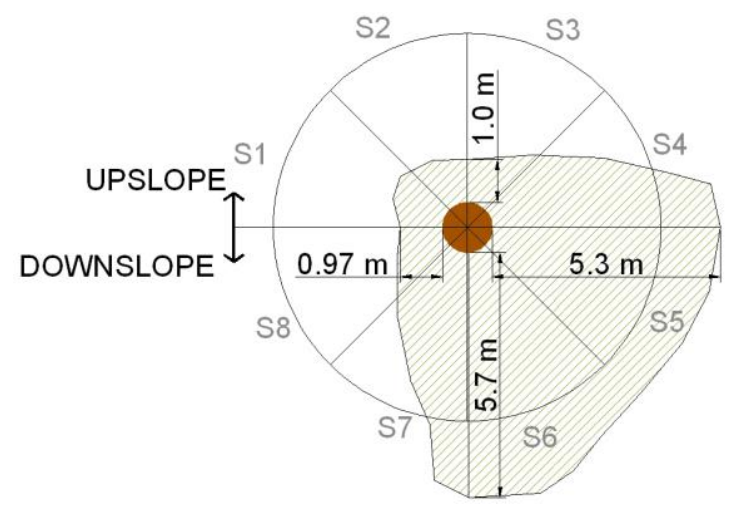

Figure 7 Sketch of the asymmetric crown of the analysed maple tree (dimensions in meters). The sectors $(\mathrm{Si}$ with $\mathrm{i}=1 \ldots .8)$ defined during the field work are shown as well 
3.2. Intrusive investigation of root distribution

The root area variation with depth according to the excavated trenches (Figure 6) is shown in Table 3.

Table 3 Root Area Ratio variation with depth corresponding to the different trenches excavated on site. Number of roots and diameter ranges with depth are also shown.

\begin{tabular}{|c|c|c|c|c|c|c|}
\hline \multirow{2}{*}{ Depth $(\mathbf{m})$} & \multicolumn{3}{|c|}{ Trench A } & \multicolumn{3}{c|}{ Trench B } \\
\cline { 2 - 7 } & $\begin{array}{c}\text { Root cross- } \\
\text { sectional } \\
\text { area }\left(\mathbf{m m}^{2}\right)\end{array}$ & $\begin{array}{c}\text { Number } \\
\text { of roots }\end{array}$ & $\begin{array}{c}\text { Diameter } \\
\text { range } \\
(\mathbf{m m})\end{array}$ & $\begin{array}{c}\text { Root cross- } \\
\text { sectional area } \\
\left(\mathbf{m m}^{2}\right)\end{array}$ & $\begin{array}{c}\text { Number } \\
\text { of roots }\end{array}$ & $\begin{array}{c}\text { Diameter } \\
\text { range } \\
(\mathrm{mm})\end{array}$ \\
\hline $0.0-0.1$ & 28964.98 & 86 & $1.5-36.0$ & 32091.82 & 13 & $2.3-35.5$ \\
\hline $0.1-0.2$ & 35482.33 & 103 & $1.5-48.5$ & 17310.47 & 19 & $2.0-38.7$ \\
\hline $0.2-0.3$ & 21990.62 & 59 & $1.0-34.5$ & 3727.37 & 11 & $2.0-35.4$ \\
\hline $0.3-0.4$ & 2642.08 & 31 & $1.0-13.5$ & 2673.15 & 7 & $2.0-21.2$ \\
\hline $0.4-0.5$ & 1886.74 & 37 & $1.5-7.0$ & 401.15 & 6 & $2.5-5.3$ \\
\hline
\end{tabular}

3.3 Non-intrusive investigation of root distribution (GPR)

The post-processing RGB algorithm (Heckbert, 1982) applied to the radargrams captured during the field work allowed for a better distinction between the rooted and the unrooted soil (Figure 8). Clear differences between upslope and downslope conditions were observed. 


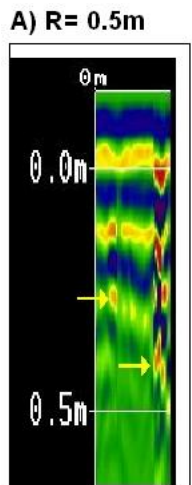

D) $\mathbf{R}=0.5 \mathrm{~m}$

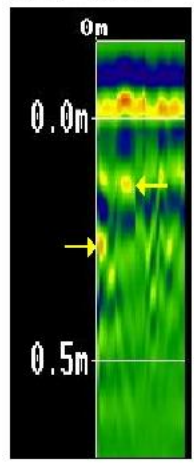

B) $R=1.5 \mathrm{~m}$

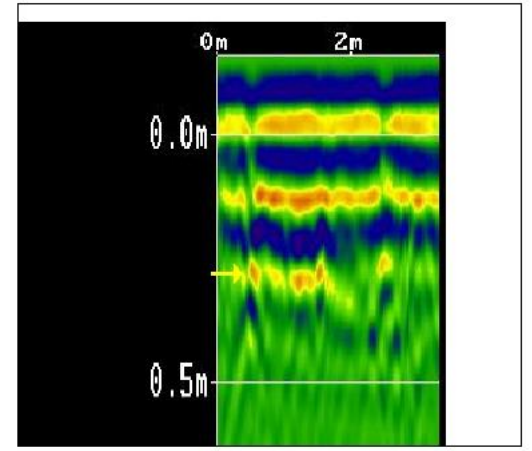

E) $R=1.5 \mathrm{~m}$

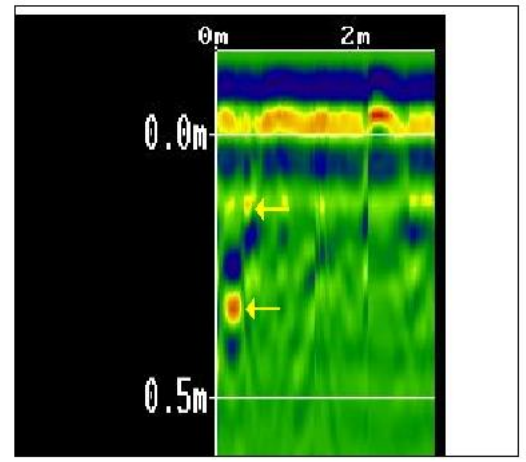

C) $\mathbf{R}=2.5 \mathrm{~m}$

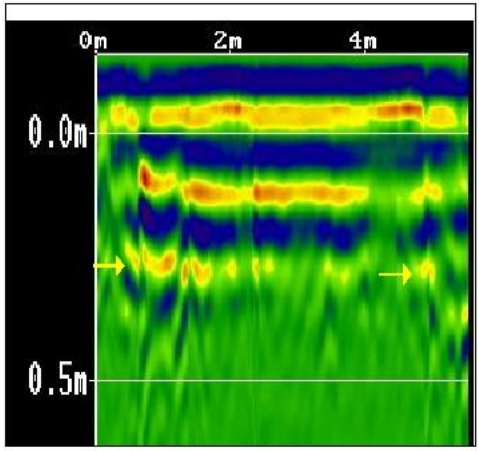

F) $R=2.5 \mathrm{~m}$

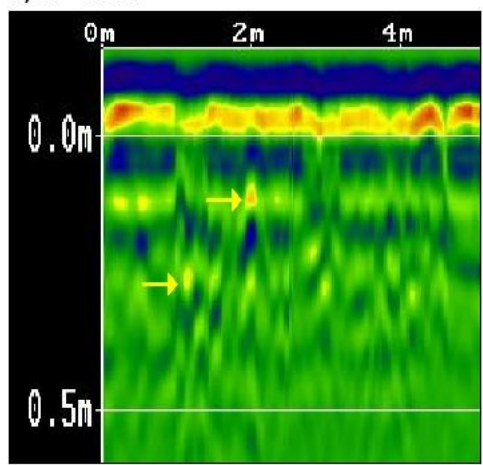

Figure 8 GPR images after applying post processing algorithms. Images A), B) and C) correspond to upslope areas. Images D), E) and F) correspond to downslope areas. Pixels showing root concentration and structural root detection are represented in red/orange/yellow colour (examples annotated with arrows).

The number of pixels representing rooted soil was counted at different depths (Table 4) and was shown to vary significantly in the upslope and downslope directions. These results could indicate the characteristic root asymmetry present in sloped terrains. An indicator of the root distribution asymmetry index can be calculated as the ratio between the preceding pixel counts (total upslope pixels/total downslope pixels). According to this, the asymmetry index value was 1.97 for our case study.

Table 4 Number of rooted soil pixels and rooted soil area variation with depth for upslope and downslope conditions according to the GPR readings. Pixel area $=8.25 \mathrm{E}-06 \mathrm{~m}^{2}$.

\begin{tabular}{|l|l|l|l|l|}
\hline \multirow{2}{*}{ Depth (m) } & \multicolumn{2}{|l|}{ Number of rooted soil pixels } & \multicolumn{2}{|c|}{ Rooted soil area $\left(\mathrm{m}^{2}\right)$} \\
\cline { 2 - 5 } & Upslope & Downslope & Upslope & Downslope \\
\hline
\end{tabular}




\begin{tabular}{|c|c|c|c|c|}
\hline $0.0-0.1$ & 46336 & 46869 & 0.382330 & 0.386728 \\
\hline $0.2-0.3$ & 38927 & 5762 & 0.321196 & 0.047544 \\
\hline $0.4-0.5$ & 18517 & 2797 & 0.152788 & 0.023079 \\
\hline $0.5-0.6$ & 2415 & 1362 & 0.019927 & 0.011238 \\
\hline TOTAL & $\mathbf{1 0 6 1 9 5}$ & $\mathbf{5 6 7 9 0}$ & $\mathbf{0 . 8 7 6 2 4 1}$ & $\mathbf{0 . 4 6 8 5 8 8}$ \\
\hline
\end{tabular}

The detected root system asymmetry is clearly shown in the pixel count variation with depth plot for both upslope and downslope conditions (Figure 9). As it can be seen, the asymmetry increases with the depth and the distance from the tree stem.
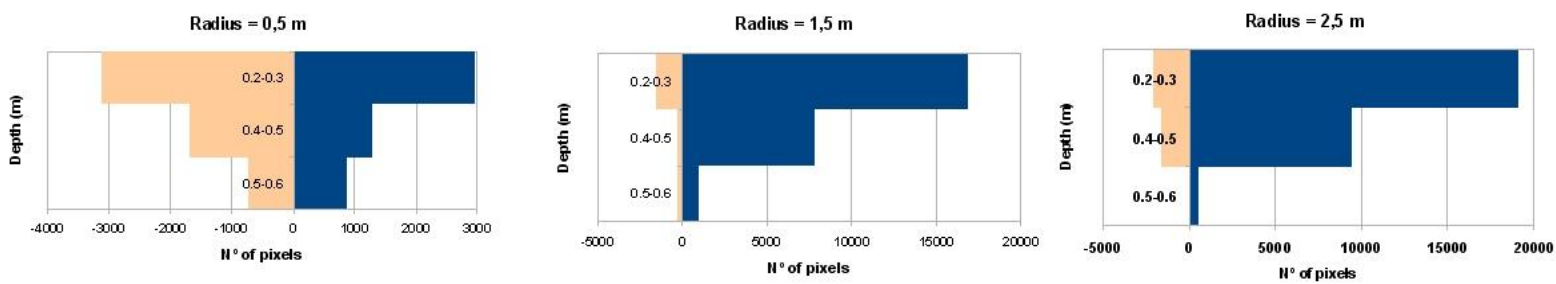

Figure 9 Root distribution with depth as interpreted from the GPR imagery. The plots show the number of pixels containing roots versus depth below ground level. The upslope area is represented in blue while the downslope area is represented in red colour. A clear asymmetry develops as distance from the tree stem increases from $0.5 \mathrm{~m}$ to $2.5 \mathrm{~m}$.

\subsection{Comparison between intrusive and non-intrusive investigations}

The downslope GPR scan for the $0.5 \mathrm{~m}$ radius path (Figure $8 \mathrm{D}$ ) was compared to the downslope trench profile data (trench A; Figure 6) given the good correspondence between their extent, location and development (trench A is very similar to the semicircular path followed in the $0.5 \mathrm{~m}$ downslope path) (Figure $5 \mathrm{~A}$ ).

The downslope GPR radargram was also visually compared to the trench profile data. Good correspondence between the GPR detected roots or root clusters and the trench profile technique outcome was found (figure 10). It is worth noting that the trench A location and development correspond to the central part of the GPR radargram (Figures 5A and 10). 


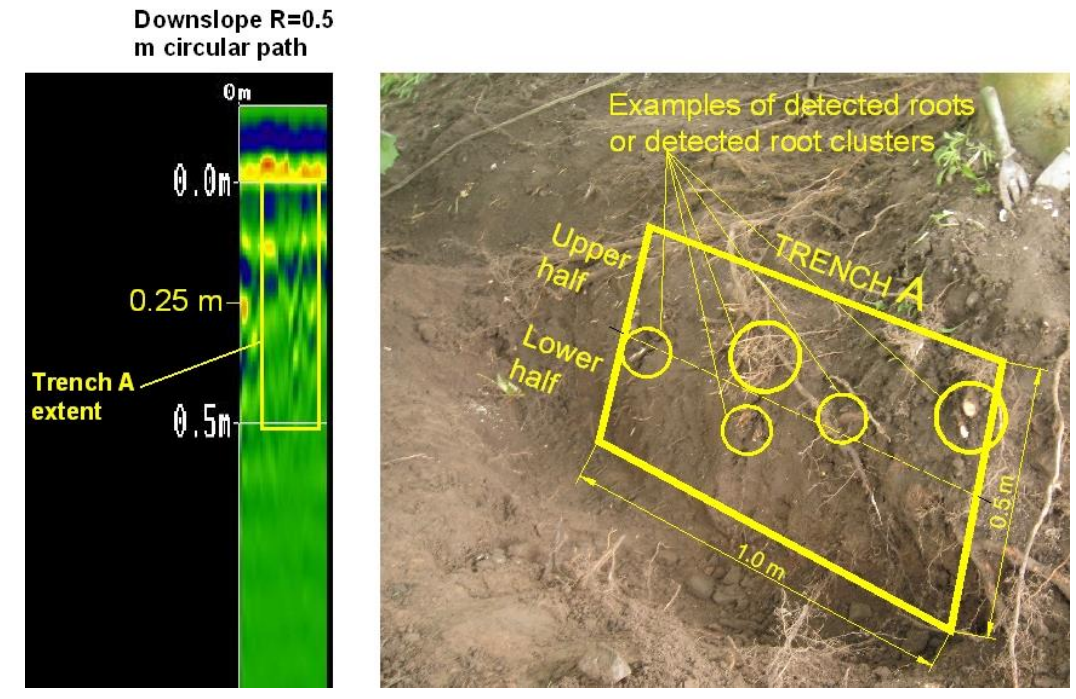

Figure 10 Downslope $0.5 \mathrm{~m}$ radius circular path radargram and trench A picture. Most of the roots detected by the GPR are concentrated within the first $0.25 \mathrm{~m}$ of depth and this is in good correspondence with the trench A profile data. Roots or root clusters detected in the GPR radargram are highlighted with a yellow circumference. Trench A extent is shown in the radargram picture.

A good correlation between the two sets of root cross-sectional area data was found (Figure 11). The other paths could not be compared to the trenches due to the differences in the position of soil volume explored.

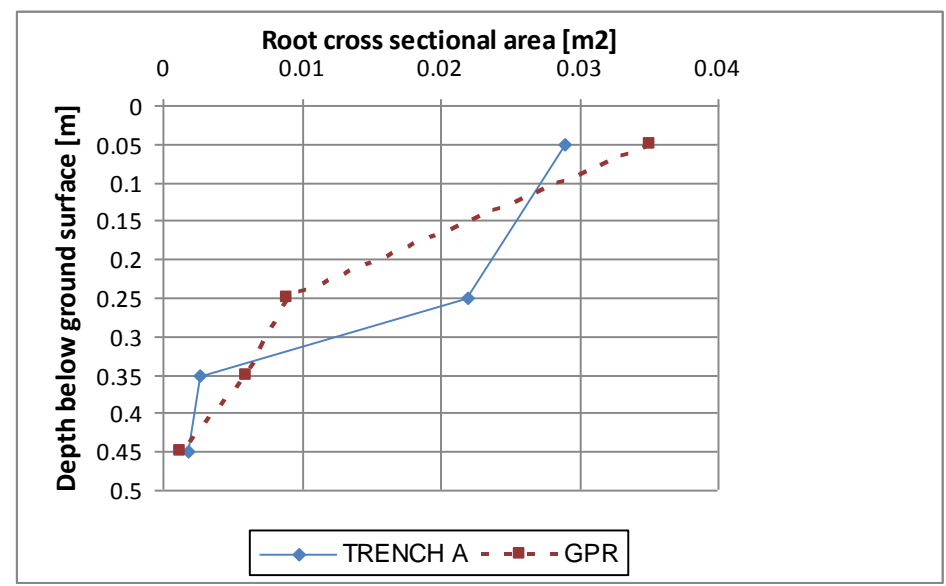

Figure 11 Comparison between the area of roots identified in downslope trench (trench A) and the area of roots inferred from GPR pixel count for the $R=0.5 \mathrm{~m}$ downslope path.

3.5. Combination of GPR results and theoretical root distribution model

Using the intrusive and non-intrusive investigations, the input parameters for the root spread model (Laio et al., 2006; Preti et al., 2010) are as follows: 
- $\mathrm{b}_{\mathrm{m}}^{\prime}=0.167 \mathrm{~m}$ according to a conservative root cluster vertical distribution analysis (average root total depth $=0.5 \mathrm{~m}$ and, therefore, $\mathrm{b}_{\mathrm{m}}{ }_{\mathrm{m}}=0.5 / 3$ )

- $\operatorname{Ar}_{0}=0.04 \mathrm{~m}^{2}($ Table 3$)$

Regarding the distribution of root cross-sectional area $(\operatorname{Ar}(z))$ with soil depth, the model outputs and the trench profile data are compared (Figure 12). As it can be seen, when using the root depth value obtained from the GPR radargrams analyses $\left(b_{m}^{\prime}=0.167 \mathrm{~m}\right)$, $a$ good fit between the theoretical model output and the profile trenches field work data was found in the lateral zones (Figure 12B), while some discrepancies were noted in the downslope zone (Figure 12A).

A)

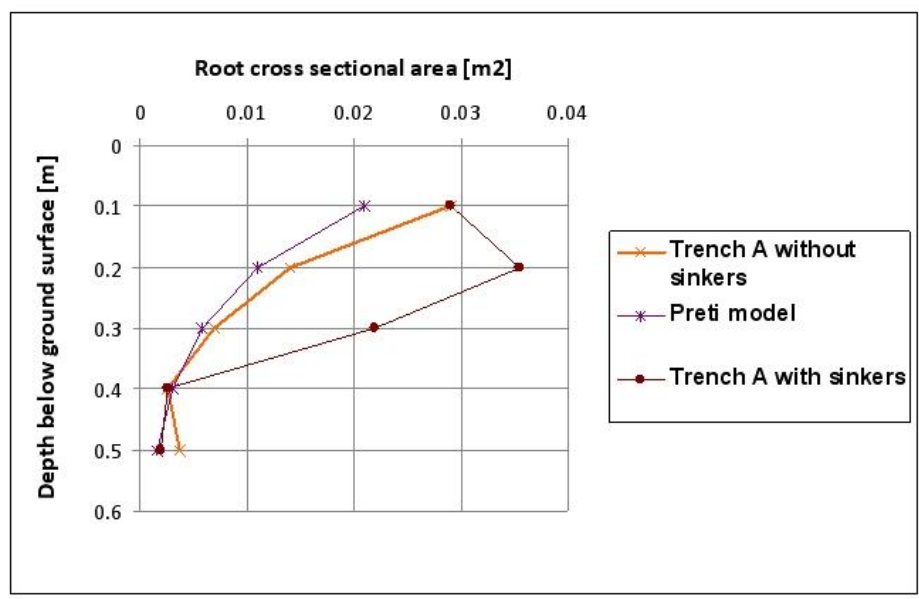

B)

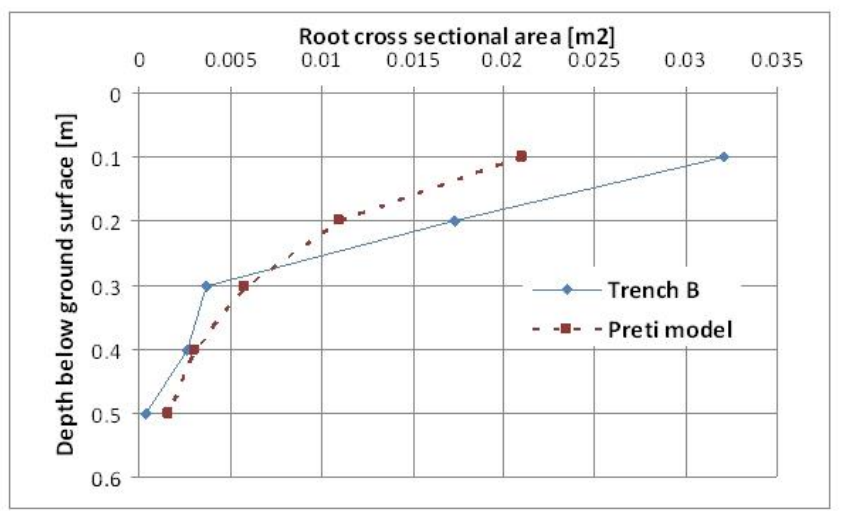

Figure 12 A) Comparison between the root cross sectional area measured in the downslope trench (trench A) with and without the detected sinker roots and root cross sectional area (CSA) predicted when using the theoretical model output, B) Comparison between the root cross sectional area measured in the lateral trench (trench B) and root cross sectional area predicted when using the theoretical model output. 


\section{Discussion}

\subsection{GPR and root distribution theoretical model}

As shown by the GPR radargrams, most of the root cross sectional area was confined within the topmost $0.5 \mathrm{~m}$ of the soil and was mainly demonstrated as shallow lateral roots. Structural roots were detected with the GPR as shown in the radargrams (Fig. 8). However, the signal collected in the radargram showed an elongated linear reflection that could be produced by a non-perpendicular insertion of the roots in the ground (i.e. crossing angle of less than $45^{\circ}$ with respect to the radar signal; Butnor et al., 2001; Barton and Montagu, 2004) or due to the presence of more than one root at a given location (i.e. nondiscrete objects; Butnor et al., 2001; Barton and Montagu, 2004). Consequently, an accurate determination of the real root cross section area, in principle, could not be derived from this technique. However, based on the similarity of the root distribution curves from GPR and intrusive investigation (Figs 10 and 11), our protocol was shown to be effective for detecting both the location of the structural tree roots and the fine root clusters and it could constitute a good non-invasive technique to readily quantify the amount of root-reinforced soil. In this sense, our investigation detected a higher root density within the upslope scanned sections (Figures 8 and 9), confirming the preferential root growth due to the adaptation of the tree to the sloped terrain as postulated in the literature (e.g. Chiatante et al., 2003).

The GPR method has a limitation in that the profile direction should ideally be perpendicular to the strike of the root. However, the variable nature of tree roots caused distortions in signal reflection making the data interpretation more difficult. The GPR image processing method used in this work proved to be effective for improving the identification of the horizontal and vertical root distribution patterns. However, there is room for the refinement of the image processing protocols. For instance, by establishing different thresholds in terms of the root pixel value, a more realistic estimation of the total crosssectional root area within a given soil horizon could have been obtained. 
Differences between the upslope and downslope root distribution patterns were detected (Figure 8 and 9; Table 4). Thus, the differentiation between big, anchoring roots present in upslope areas and root clusters present in downslope areas was possible by using a GPR. These results coincide with the mechanically optimised root system shape postulated by Mattheck (2011) (Figure 1B).

The good correlations found between the GPR output and the profile wall data (Figs 10 and 11) can be explained because GPR scans mainly detect the rooted soil zone (not individual roots). Differences between GPR and the trench method (Figs 10 and 11) were mainly found near the $0.25 \mathrm{~cm}$ of depth. This could be due to the difference of distance between the central part of the downslope GPR circular path and trench A with respect to the tree stem (Figure 5A). Unlike the GPR readings (central part of Figure 8D), several big sinkers roots were detected near the tree stem in trench A (Table 3). Hence, in the CSA comparison, the general trend is well reflected but some differences because of the different explored planes are also reflected. Therefore, a proportional correlation between this rooted soil area values and the presence/absence of roots can be expected. This reasoning would be applicable to both the horizontal and the vertical root distribution analysis and, hence, it highlights the potential of the GPR as a non-invasive technique providing information to be used in the theoretical root distribution models.

Figure $12 \mathrm{~A}$ also shows differences between the outcomes of trench $\mathrm{A}$ and the theoretical model (Preti et al..2010) at a depth of $0.25 \mathrm{~m}$. As noted before, this could be due to the thick sinker roots detected and measured in trench A. When the CSA (root cross sectional area) of these sinker roots is removed (Figure 12A) the resemblance between the two results is very satisfactory.

Figure 12B shows a good correlation between the theoretical model and the trench $\mathrm{B}$ measurements. This is due to the fact that trench B is located further away from the tree stem and the effects of the aforementioned sinker roots on the CSA value in the downslope area are not present. These results shows a good correlation between the two trends detected by both methods. 
In both cases, if the output were to be used in a root reinforcement model (e.g. Wu et al., 1979), the theoretical model (Preti et al., 2010) gives results erring on the side of safety. Hence, the use of GPR estimated $b_{m}^{\prime}$ value (mean rooting depth) in the theoretical model offers good possibilities for assessing the general root distribution pattern although this should be taken with caution because the effect of large sinker roots can introduce differences in the CSA comparisons. Nevertheless, these effects are less important in terms of root reinforcement models (e.g. Wu et al., 1979) since they are based on the role played by finer roots (added cohesion) and not by big structural roots (such as the sinker roots).

Differences between the theoretical model and GPR rooted soil measurements are mainly due to the big structural root presence and this situation is especially important for GPR readings close to the tree stem. The mean rooting depth value $\left(b_{m}\right)$ used in Eq. 2 was obtained from the vertical root cluster distribution detected by the GPR field work. Therefore, the use of onsite information directly related to both the site conditions and a particular plant species, remarkably enhanced the model outcomes. If possible, in order to calibrate the GPR-theoretical model methodology it may be advisable to include a limited intrusive field work campaign which would allow for a validity confirmation of the methodology preliminary outcomes.

Although the typical bandwidths used for analysing root distribution patterns and root system architecture are commonly reported to be of the order of $400 \mathrm{MHz}$ or higher (Barton and Montagu, 2004; Guo et al., 2013; Ferrara et al., 2014; Cui et al., 2016), because of the soil type and soil moisture conditions in the study site (sandy soil with a high saturation level), the vertical resolution was considered to be accurate enough for GPR field work even for a $250 \mathrm{MHz}$ bandwidth which was the limit of the available equipment. In these site conditions, the $250 \mathrm{MHz}$ bandwidth and the $250 \mathrm{MHz}$ central frequency allowed for a vertical resolution of $0.075 \mathrm{~m}$ (Robinson et al., 2013) which was considered appropriate for detection of large structural roots and root clusters. This was vindicated by the correlation of the GPR measurements and the intrusive investigations which showed a good fit. Additionally, these results showed that the limitations posed by the equipment may be overcome for certain soil 
and vegetation conditions with a level of intrusive investigations and post-processing of the results. For other soil types and soil moisture conditions higher frequencies and bandwidths may be more appropriate in order to achieve better accuracy.

The proposed methodology offers a realistic way to characterise and analyse root systems in slope conditions at a tree scale. The results obtained can be readily used in root reinforcement models to estimate the stabilising role of tree roots in the overall slope stability (e.g. Wu et al., 1979). With the proposed approach, the sloped terrain scenarios will be more accurately analysed by means of non-invasive techniques.

\subsection{Asymmetric loading scenarios and root system asymmetry analysis}

The two loading scenarios present in the case study are the sloping terrain and the tree crown asymmetric weight distribution. The slope direction falls within the $4^{\text {th }}$ sector (Figure 13) and, given the slope inclination value (22.5), the major factor defining the tree mechanical scenario is the asymmetric load due to the tree crown shape (Figures 7 and 13). According to the tension cone method approach (Mattheck, 2011), the loads exerted on a tree generate a stress state that can be reflected by means of compression and tension zones (Fig 1). Every load effectively pushes a $90^{\circ}$ compression cone in front and pulls a $90^{\circ}$ tension cone behind. This idea is based on the fact that, in the stress distribution of a single force, around $80 \%$ of the occurring radial stress will be included by a $90^{\circ}$ cone symmetrically placed in front of the force and behind it (Mattheck, 2011). In the case study, sectors S1 and S2 would represent the tension cones derived from the tree crown asymmetry effect while sector S3 and S4 (including a part of S5) represents the tension cones derived from the slope conditions (Figure 13). 


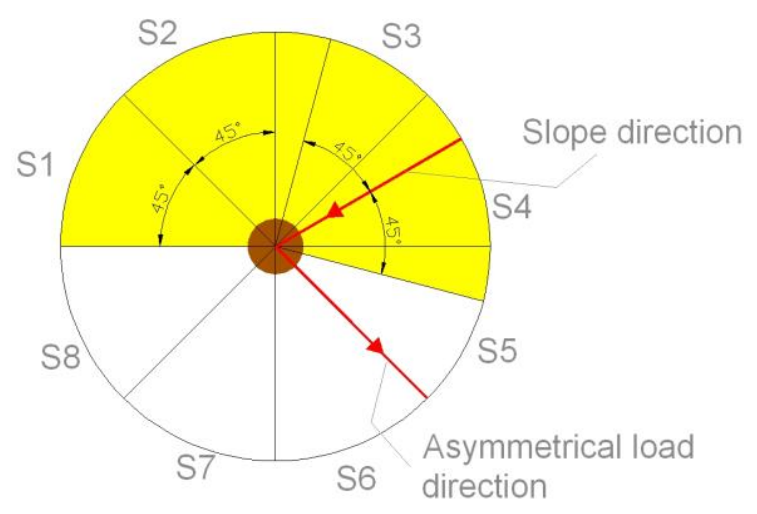

Figure 13 Loading scenarios in the study case (slope direction and asymmetric load due to tree crown shape. Tension cones (in yellow) are formed according to Mattheck (2011).

As a result, S1-S4 sectors correspond to the areas where the roots would be mainly loaded in tension and could be assimilated to a virtual general upslope condition. Contrariwise, S5-S8 sectors approximately correspond to the areas where the roots are loaded in compression (and bending) and could be assimilated to a virtual general downslope condition.

The lateral root distribution around the maple tree coincides with the conclusions reached by other authors (Chiatante et al., 2003; Mattheck, 2011) showing that under lateral loading conditions (e.g. wind, sloping terrain, etc.), the upslope roots grow thicker in an attempt to accumulate a bigger surface for developing friction strength within the soil. In this way the transfer of tension to the soil via friction is improved (Stokes et al., 1996) and the roots being under tension forces tend to be elongated unlike those under compression which tend to be shortened (Mattheck et al., 1995). In this sense, the tension zone included the major root area (Figure 13) and it is where the lateral roots were found to be larger. The shaded area in Figure 13 (tension area) matches very well with the root distribution encountered during the intrusive investigations (Figure 13; S1-S4 tension area and a S5-S8 compression area). The contact areas between S8-S1 and S4-S5 are also influenced by the tension conditions.

The former has implications related to tree stability and root morphology. The necessary tension for tree stability is achieved by means of extending lateral roots located opposite to the different loading scenarios (see Figure 14). In the middle of the tension area 
(S2-S3 bisector) some large tension roots were found. Secondary roots following $45^{\circ}$ angles (Mattheck, 2011) with respect to primary roots (Figure 14) were also found, proving that the major loading in this zone (S1-S4 sectors) is tension.

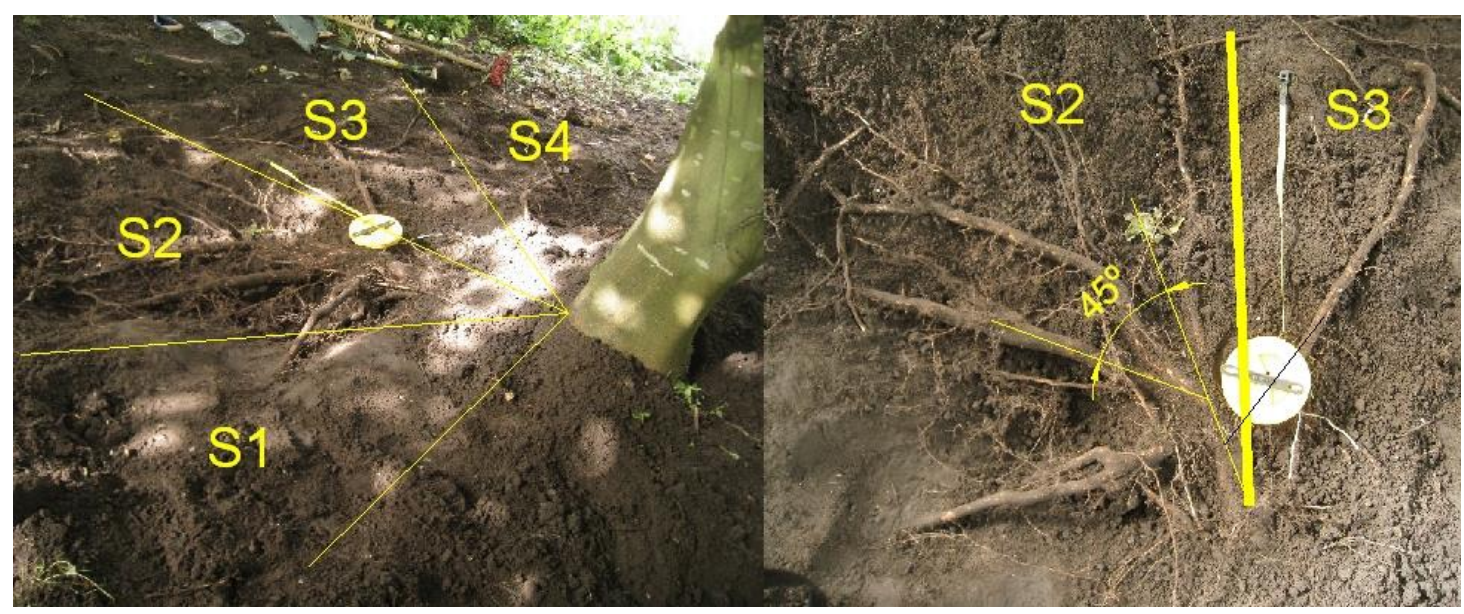

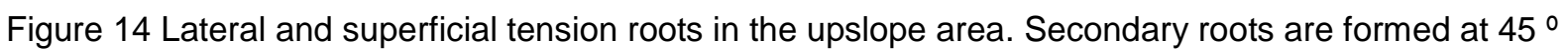
from primary roots.

As shown by published literature, trees on steep slopes develop fewer but larger lateral roots as the root plate mass is shifted more to the upslope side (Dilorio et al., 2005; Danjon et al., 2005). As it was observed (Figure 15), downslope areas presented deeper roots while upslope areas tended to have more superficial roots that covered a larger area (Figures 8 and 9).

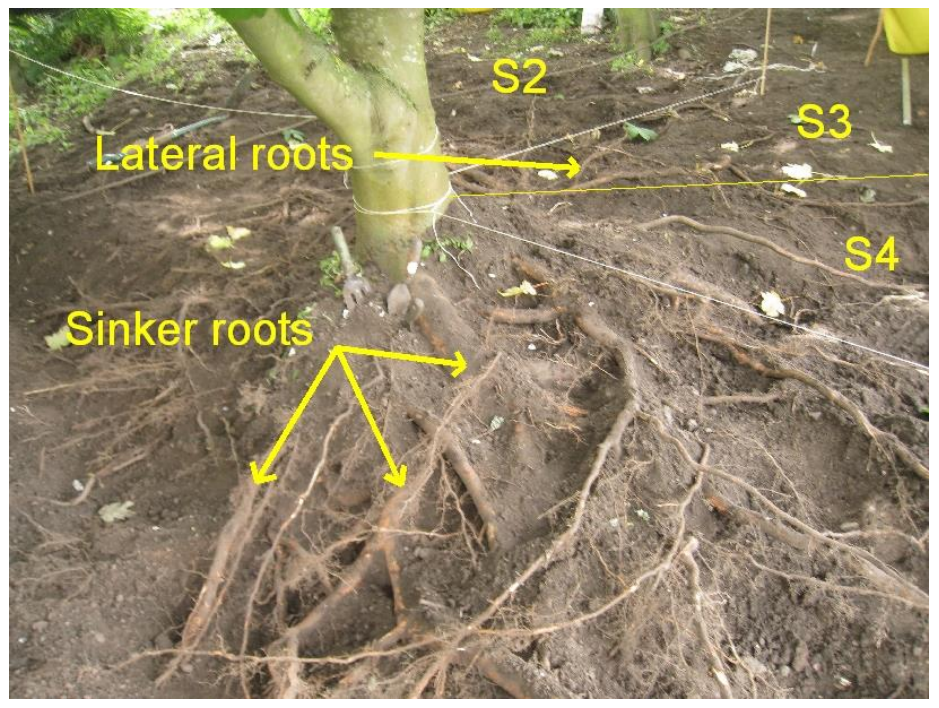


Figure 15 In sectors S1 to S4 superficial lateral roots are abundant unlike sectors S6 and S7 where sinker roots are the main root type

The diameters of the structural roots, which may be defined as those lateral roots having a diameter greater than $20 \mathrm{~mm}$ at a distance of $200 \mathrm{~mm}$ from the tree trunk (Mickovski and Ennos, 2001), were larger and longer in the upslope area (Figures 5B, 9 and 15; Table 3). These structural roots emerged from the first $200-300 \mathrm{~mm}$ of the taproot depth. As explained before, these results connect with the idea that a bigger interbonding surface is needed in the upslope zone in order to mobilise friction between root and soil and, this was well represented in the asymmetry detected with the GPR scans (Figures 8 and 9).

It is worth noting that, as the field excavation has collected the information of root system in two trenches (Figure 6), it would have been expected that comparison and analysis of all the GPR profiles with the root distribution in the trenches would be presented. However, due to the apparent lack of spatial similarity and proximity to the trench profile locations, we could only present the comparison between the $0.5 \mathrm{~m}$ radius circular path and the trench A profile data (Fig 12A). In this respect, a comparison between GPR and profile wall outcomes would likely have been more feasible if linear transects had been used.

Although root distribution may change according to different parameters such as tree competence increase or tree age (Butnor, 2011) the validity of the inner logic of the proposed methodology is readily transferable to these other field work scenarios since the GPR readings will always reflect the influence and effects of the preceding parameters. In general terms, if a good calibration is accomplished (which means that both soil type and soil moisture are correctly determined and included into the GPR device settings) every parameter affecting root system distribution (e.g., tree age, tree competence, root moisture content, etc.) would implicitly be included into the GPR radargrams and hence into the theoretical distribution model inputs $\left(b_{m}^{\prime}\right)$. Indeed, the proposed methodology could be used for comparing variations of the preceding variables such as tree age, root system type, tree competence, slope values, etc. 
The limitations on the use of GPR are mainly due to field site accessibility problems, excessive bushy vegetation around the selected tree specimen, abrupt topography, etc. In these cases, the use of circular paths around the tree could be unfeasible and the only possibility could be following linear transects as close as possible to the selected tree which, on the other hand, may allow better comparison between GPR profiles and root distribution derived from trenching.

\section{Conclusions}

1) Ground penetrating radar can be used to identity root presence and to compare the soil-root reinforced area for upslope and downslope conditions.

2) GPR can be considered as a useful, and cost-effective in-situ technique from a tree and slope stability analysis point of view as it permits the non-invasive exploration of natural slope profiles and its outcome presents a great potential to be used in combination with theoretical root distribution models that can, in turn, be readily employed in combination with soil-root reinforcement models (e.g. Wu et al., 1979).

3) A mean rooting depth value was successfully derived form the GPR information and was directly input into the root spread model, overcoming its limitations for humid climates and slope conditions.

4) GPR scans were proven to be successful for inferring the asymmetric shape of root systems in sloped terrain. However, appropriate selection and calibration of the GPR equipment, together with a level of post-processing of the output data will be needed for different soil types and moisture conditions.

5) With the proposed approach the theoretical model was proven to be a useful tool for rooted soil vertical and horizontal distribution estimation although results close 
to the tree stem must be taken with caution given the sinker roots important influences.

6) The different loading conditions (e.g. slope conditions, asymmetric weights, etc.) analysed were directly related to the asymmetric root system distribution. Each loading scenario case explained part of the existing root distribution pattern and morphology. The aforementioned general virtual downslope/upslope conditions were shown to correspond with both lateral structural roots distribution (mainly concentrated in the general virtual upslope condition zone) and sinker roots (mainly located in the general virtual downslope condition zone). Particularly, the tension cone method (Mattheck, 2011) was proven to be very useful in depicting and explaining the lateral root distribution pattern.

An improvement and enhancement of the proposed methodology could be accomplished by taking into account the following strategies:

- The use of GPR linear transects and their comparison with trench profiles in combination with the approach presented herein would enhance the methodology outcome.

- The use of different bandwidths and antenna central frequencies.

- The use of different root distribution theoretical models.

- The use of other GPR variables as model inputs.

- The analysis of different tree species and tree densities could contribute to shed light on the true potential of the proposed methodology.

- The analysis of how tree age and surrounding trees' competition influence the root system spread on sloping terrain could aid to improve models' predictions, in particular, and the use of vegetation on slope stability, in general.

- The analysis of slope value influence. 
The authors would like to encourage further researchers and practitioners to employ the proposed non-invasive methodology for potential improvements of the approach and its validation in other field work scenarios.

\section{Acknowledgements}

The work on this study has been carried out as part of an Erasmus+ Programme for Support of Student Mobility for Traineeships.

\section{References}

Annan, A. P., Davis, J. L., 1976. Impulse radar sounding in permafrost. Radio Science, Vol. 11, 383394.

Barthelme, S., 2015. Imager: Image processing library based on Clmg. R package version 0.14. http://CRAN.R-project.org/package=imager

Barton, C. V. M. and Montagu, K., 2004. Detection of tree roots and determination of root diameters by ground penetrating radar under optimal conditions. Tree Physiology 24:1323-1331.

Bassuk, N., Grabosky, J., Mucciardi, A., Raffel, G., 2011. Ground-penetrating radar accurately locates tree roots in two soil media under pavement. Arboriculture \& Urban Forestry. 37(4):160-166.

Baumgartner, A., Harzheim, L., Mattheck, C., 1992. SKO (soft kill option): the biological way to find and optimum structure topology. Int J Fatigue № 6 (1992) pp 387-393.

BGS (British Geological Survey), 2013. 1:50 000 Geology [SHAPE geospatial data], Scale 1:50,000, Tiles: sc067, Updated: 1 October 2013.

Böhm, W., 1979. Methods of studying root systems, Springer Verlag Berlin, pp 275.

Bourrier, F., Kneib, F., Chareyre, B., Fourcaud, T., 2013. Discrete modelling of granular soils reinforcement by plant roots. Ecol. Eng. C 61, 646-657.

BS1377, 1990. Methods of test for soils for civil engineering purposes.

Butnor, J., 2011. Monitoring tree roots over time with GPR; doi: 10.4133/1.3614293.

Butnor, J. R., Doolittle, J. A., Kress, L., Cohen, S. and Johnsen, K. H., 2001. Use of groundpenetrating radar to study tree roots in the southeastern United States. Tree Physiology 21:12691278. 
Butnor, J. R., Doolittle, J. A., Johnsen, K. H., Samuelson, L., Stokes, T., Kress, L., 2003. Utility of Ground-Penetrating Radar as a Root Biomass Survey Tool in Forest Systems. Soil Science Society of America Journal 67, 1607-1615.

Butnor, J. R., Barton, C., Day, F. P., Johnsen, K. H., Mucciardi, A. N., Schroeder, R., Stover, D. B., 2011. Using Ground-Penetrating Radar to Detect Tree Roots and Estimate Biomass. Measuring Roots. 2011: 213-245.

Chiatante, D., Scippa, S. G., Di Lorio, A., Sarnataro, M., 2001. Root architecture modified by mechanical stress in seedling of Fraxinus ornus L. and Spartium junceum L. growing on slopes. In Proceedings of the International Conference- Thessaloniki Greece. Ed. K. Radoglou. pp. 477-482.

Chiatante, D., Scippa, S. G., Di Lorio, A., Sarnataro, M., 2003. The influence of steep slopes on root system development. Journal of Plant Growth Regulation 21, 247-260.

Coder, K. D., 2010. Root Strength \& Tree Anchorage. University of Georgia Warnell School of Forestry \& Natural Resources monograph publication WSFNR10-19*. Pp.88.

Coutts, M. P., 1983. Root architecture and tree stability. Plant Soil 71:171-188.

Crook, M. J., Ennos, A. R., 1996. The anchorage mechanics of deep root larch, L. europea, L. japonica. J Exp Bot 47:1509-1517.

Cui, X., Guo, L., Chen, J., Chen, X., Zhu, X., 2016. Estimating tree-root biomass in different depths using ground penetrating radar: evidence from a controlled experiment. IEEE Transactions on geoscience and remote sensing, doi: 10.1109/TGRS.2012.2224351.

Danjon, F., Fourcaud, T., Bert, D., 2005. Root architecture and wind-firmness of mature Pinus pinaster. New Phytologist 168:387-400.

Davis, J. L., Annan, A. P., 1989. Ground-penetrating radar for high-resolution mapping of soil and rock stratigraphy. Geophysical Prospecting, Vol. 37, 531-551.

Dilorio, A., Lasserre, B., Scippa, G. S., Chiatante, D., 2005. Root system architecture of Quercus pubescens trees growing on different sloping conditions. Annals of Botany 95:351-361.

Ferrara, C., Barone, P. M., Salvati, L.,Pettinelli, E., 2014. Ground penetrating radar as remote sensing technique to investigate the root system architecture. Applied ecology and environmental research 12(3): 695-702, doi: 10.15666/aeer/1203_695702.

Fan, C.-C., 2012. A displacement-based model for estimating the shear resistance of root-permeated soils. Plant and Soil 355 (1-2), 103-119. 
González-Ollauri, A. and Mickovski, S. B., 2016. Using the root spread information of pioneer plants to quantify their mitigation potential against landslides in temperate humid climates. Submitted to the Ecological Engineering Journal. Unpublished.

Guo, L., Chen, J., Cui, X., Fan, B., Lin, H., 2013. Application of ground penetrating radar for coarse root detection and quantification: a review. Plant Soil, 362: 1-23.

Heckbert, P., 1982. Color image quantization for frame buffer display. Computer Graphics, 16(3):297307.

Hijmans, R. J., 2014. Raster: Geographic data analysis and modelling. R package version 2.312. http://CRAN.R-project.org/package=raster

Hruska, J., Cermák, I., Sustek, S., 1997. Mapping of tree root systems with ground penetrating radar. Tree Physiology 19: 125-130.

Laio, F., D'odorico, P., Ridolfi, L., 2006. An analytical model to relate the vertical root distribution to climate and soil properties. Geophysical Research Letters, 33:L18401.

Mattheck, C., 2011. Thinking Tools after Nature. Verlag Forschungszentrum Karlsruhe.

Mattheck, C., Breloer, H., Bethge, K. A., Albrecht, W. A., Zipse, A. W., 1995. Use of the fractometer to determine the strength of wood with incipient decay. Journal of Arboriculture 21(3): 105-112.

Mattheck, C., Berthge, K, 2011. Root Mechanics Based on "Thinking Tools after Nature". Poster of the Institute for Applied Materials. Karlsruhe Institute of Technology, http://bibliothek.fzk.de/zb/berichte/Mattheck-Poster-110503.pdf.

McKnight, T. L. \& Hess, D., 2000. Climate Zones and Types: The Köppen System. Physical Geography: A Landscape Appreciation. Prentice Hall. pp. 226-235.

Mickovski, S. B. and Ennos, A. R., 2001. The root symmetry and architecture in two Pinus species grown in different environmental conditions. In: Proceedings of the 6th Symposium of the International Society of Root Research, pp 454-455.

Mickovski, S. B. \& Ennos, A. R., 2003. Anchorage and asymmetry in the root system of Pinus peuce. Silva Fennica 37(2): 161-173.

Mickovski, S. B., van Beek, L. P. H., Salin, F., 2005. Uprooting resistance of vetiver grass (Vetiveria zizanioides). Plant Soil 278:33-41.

Nicoll, B. C., Ray, D., 1996. Adaptive growth of tree root systems in response to wind action and soil conditions. Tree Physiol 16:891-898. 
Norris, J. E., Stokes, A., Mickovski, S. B., Cameraat, E., van Beek, R., Nicoll, B. C., Achim, A. (Eds.), 2008. Slope Stability and Erosion Control: Ecotechnological Solutions. Springer, pp. 100-106.

Olhoeft, G R., 1984. Applications and limitations of ground penetrating radar. 147-148 Society of Exploration Geophysicists, 54th Annual International Meeting, Atlanta (abstract).

Pollen, N., Simon, A., 2005. Estimating the mechanical effects of riparian vegetation on stream bank stability usin a fiber bundle model, Water Resour Res 41:W07025, doi.10.1029/2004WR003801.

Preti, F., Giadrossich, F., 2009. Root reinforcement and bioengineering stabilisation by Spanish broom. Hydrol. Earth Syst. Science 13: 1713-1726.

Preti, F., Dani, A., Laio, F., 2010. Root profile assessment by means of hydrological, pedological and above-ground vegetation information for bio-engineering purposes. Ecol. Eng. 36, 305-316.

R Core Development Team, 2014. R: A language and environment for statistical computing. Vienna, Austria: R Foundation for Statistical Computing URL: http://www.R-project.org

Raz-Yaseef, N., Koteen, L., Baldocchi, D. D., 2013. Coarse root distribution of a semi-arid oak savanna estimated with ground penetrating radar. Journal of Geophysical Research: Biogeosciences, Vol. 118, 1-13, doi:10.1029/2012JG002160.

Reneau, S. L., Dietrich, W. E., 1987. Size and location of colluvial landslides in a steep forested landscape. In Erosion and Sedimentation in the Pacific Rim, Proceedings of the Corvallis Symposium, August 1987. IAHS Publication 165; 39-48.

Robinson, M, Bristow, C., McKinley, J., Ruffell, A., 2013. Ground Penetrating Radar. Geomorphological Techniques, Part 1, Sec. 5.5 (2013). ISSN 2047-0371. British Society for Geomorphology

Schwarz, M., Lehman, P., 2010. Quantifying lateral root reinforcement in steep slopes-From a bundle of roots to tree stand. Earth Surface Processes and Landforms 03/2010; 35(3):354 - 367. DOI: 10.1002/esp.1927.

Shrestha, M. B., Horiuchi, M., Yamadera, Y., Miyazaki, T., 2000. A study on the adaptability mechanism of tree roots on steep slopes. In The Supporting Roots of Trees and Woody Plants: Form, Function and Physiology. Developments in Plant and Soil Sciences. Ed. A Stokes. Kluwer Academic Publishers, Dordrecht, 51-57.

Singh, K. K. K., 2006. Application of Ground Penetrating Radar for hydro-geological study. Journal of Scientific \& Industrial Research. Vol. 65, February 2006, pp. 160-164. 
Stokes, A., Guitard, D., 1997. Tree root response to mechanical stress. Biology of root formation. New York: Plenum Press, p 227-236.

Stokes, A., Ball, J., Fitter, A. H., Brain, P., Coutts, M. P., 1996. An experimental investigation of the resistance of model root systems to uprooting. Ann Bot 78:415-421.

Stokes, A., Nicoll, B. C., Coutts, M. P., Fitter, A. H., 1997. Responses of young Sitka spruce clones to mechanical perturbation and nutrition: effects on biomass allocation, root development, and resistance to bending. Can J For Res 27:1049-1057.

Stokes, A., Fourcaud, T., Hruska, J., Cermák, I., Nadyezdhina, V. and Praus, L., 2002. An evaluation of different methods to investigate root system architecture of urban trees in situ: I. ground-penetrating radar. Journal of Arboriculture 28(1):2-10.

Stokes, A., Atger, C., Bengough, A., Fourcaud, T., Sidle, R., 2009. Desirable plant root traits for protecting natural and engineered slopes against landslides. Plant and Soil 324 (1), 1-30.

Tanikawa, T., Ikeno, H., 2016. Leaf litter thickness, but not plant species, can affect root detection by ground penetrating radar. Plant Soil. Doi: 10.1007/s11104-016-2931-0.

Tron, S., Dani, A., Laio, F., Preti, F., Ridolfi, L., 2014. Geophysical Research Abstracts. Vol. 14, EGU2012-10739, 2012. EGU General Assembly 2012.

Tsutsumi, D., Kosugi, K., Mizuyama, T., 2003. Root system development and water extraction model considering hydrotropism. Soil Sci Soc Am J 67:387-401.

Tsutsumi, D., Kosugi, K., Mizuyama, T., 2004. Three-dimensional modeling of hydrotropism effects on plant root architecture along a hillslope. Vadose Zone J. 3, 1017-1030.

Van Noordwijk, M., Brouwer, G., Meijbroom, F., Oliveira, M. R. G., Bengough, A. G., 2000. Trench profile techniques and core break methods. In AL Smit (ed), Root methods: A handbook. Springer, Berlin, pp 211-233.

Wu, T. H., Mckinnell, W. O., Swanston, D. N., 1979. Strength of tree roots and landslides on PrinceOf- Wales-Island. Alaska. Canadian Geotechnical Journal 16(1): 19-33.

Zenone, T., Morelli, G., Teobaldelli, M., Fischanger, F., Matteuci, M., Sordini, M., Armani, A., Ferre, C. Chiti, T., Seufert, G., 2008. Preliminary use of ground penetrating radar and electrical resistivity tomography to study tree roots in pine forests ad poplar plantations. Functional Plan Biology, 2008, 35:1047-1058; doi: 10.1071/FP08062. 